\title{
Investigation of the Stability of Oxadiasole and Their Analogs Using Quantum Mechanics Computation
}

\author{
Masoud Karimi \\ Department of Chemistry, Faculty of Science, Islamic Azad University, Arak Branch, Arak, Iran \\ Email: masoudkarimi67@gmail.com
}

Received 20 November 2015; accepted 10 January 2016; published 13 January 2016

Copyright (C) 2016 by author and Scientific Research Publishing Inc.

This work is licensed under the Creative Commons Attribution International License (CC BY).

http://creativecommons.org/licenses/by/4.0/

(c) (i) Open Access

\section{Abstract}

This study aimed at investigating factors affecting the stability as well as structural properties of different Oxadiasole and Thiadiasole isomers based on theoretical level B3LYP/6-311+G**, Nuclear Magnetic Resonance (NMR), and Nucleus-independent Chemical Shift (NICS). Qualitative relationships between relative stabilities of 1,2,3-0xadiazole, 1,2,4-0xadiazole, 1,2,5-0xadiazole and 1,3,4-0xadiazole were obtained. Aromatic stabilization energy (ASE), aromatic ring current (NICS), HUMO-LUMO gaps, electro-negativity (X), hardness $(\eta)$, softness (S), electro-philicity $(\omega)$ and structural parameters were also calculated in the same theoretical level. The results show that 1,3,4Oxadiazole is more stable than 1,2,3-0xadiazole, 1,2,4-0xadiazole and 1,2,5-Oxadiazole. Unlike the trends observed in 0xadiazoles, 1,2,5-Thiadiazole isomer is more stable than other corresponding Isomers.

\section{Keywords}

Oxadiazole, DFT, $A b$ Initio, NMR

\section{Introduction}

Most components consisted of five-member heterocyclic rings have special chemical properties and are used for multipurpose biological activities [1]. Oxadiazole is an aromatic heterocyclic with $\mathrm{C}_{2} \mathrm{H}_{2} \mathrm{~N}_{2} \mathrm{O}$ formula. It has 4 isomers including 1,2,4-Oxadiasole, 1,2,5-Oxadiasole and 1,3,4-Oxadiasole as its well-known isomers and 1,2,3Oxadiasole as its only unstable isomer [2] [3] (a diazoketone tautomer). Stable Oxadiasole exists in an extensive range of drugs including Raltegravir, Butalamine, fasiplon, oxolamine, pleconaril [4]-[7]. Thiadiasoles $\left(\mathrm{C}_{2} \mathrm{H}_{2} \mathrm{~N}_{2} \mathrm{~S}\right)$ are categorized based on their pharmaceutical effects and the emphasis is on their versatility in pharmaceutical 
chemistry [8] [9]. Unique properties of Thiadiasoles are also a special subject that is investigated with regards to their effects on various activities. Thiadiasole is one of thebiological iso-esters of Oxadiasoles which are considered for their pharmaceutical properties [10] [11]. They are five-member hetrocyclic components that contain Nitrogen, oxygen, and sulfur atoms. They’ve served as oxidation inhibitors, cyanine dyes, metal chelating agents and metal corrosion agents. Thiadiasoles which had been tested against various diseases successfully were important to pharmaceutical chemistry because of their various applications [2] [12].

Oxidiasole is an important heterocyclic ring consisted of two Nitrogens and one Oxygen in a five-membered ring. Oxidiasoles have different analogs based on the placement of Oxygen and Nitrogen atoms in the ring. The aromatic properties of these analogs along with Thiadiasoles derivatives and also these properties' effects on the stability of their different varieties are discussed here. In Figure 1, different Oxidiasoles derivatives are illustrated.

Oxidiasoles are usually employed for designing bioactive or affective agents on organisms (entities). This interesting group of components have various biological activities such as antibacterial, anti-inflammatory, antituberculosis, anticonvulsants and etc. [13] [14].

In this study, effective factors of different Oxidiasoles' isomers on component's structural stability are investigated, based on B3LYP/6-311+Gtheoretical level** and nuclear magnetic resonance (NMR) [15]-[19].

\section{Methods}

This study was conducted in several gas phases. First, the isomers' structures were optimized using semi-empirical quantum mechanics method. Then, the required Z-Matrix was prepared for using in Gaussian 03 program. Next, Stereo-electron thermodynamic parameters were computed to obtain final optimized structures as well as to calculate electron energies using GIAO/B3LYP/6-311+G level** that is one of the high levels abinithio quantum mechanics available in Gaussian program [20] [21].

Furthermore, according to relative density theory, several total chemical reactivities descriptorssuch as hardness index, chemical potential, softness, electronegativity and electro-philicity were introduced [22]-[24]. The results show that molecular stability depends on hardness. Pauling introduced electronegativity as a force from one atom to the other to maintain and capture its electrons. Equations 1 to 3 show hardness $(\eta)$, chemical potential $(\mu)$, and electronegativity $(X)$ formula, respectively.

$$
\begin{gathered}
\eta=\frac{1}{2}\left(\frac{\partial 2 E}{\partial N 2}\right)_{V(r)}=\frac{1}{2}\left(\frac{\partial \mu}{\partial N}\right)_{V(r)} \\
V(r)=\left[\frac{\partial E}{\partial N} \mu\right] \\
\chi=-\mu=-\left[\frac{\partial E}{\partial N}\right]_{V(r)}
\end{gathered}
$$

Parr et al. investigated electrophilicity as a measurement unit for decreasing energy that considered the maximum of electrons exchanged between electron donor and electron acceptor [25]-[27]. They defined electrophilicity in the following equation:

$$
\omega=2 / 2 \eta
$$

If one of two molecules reacting together acts as an electrophil, that molecule has larger electrophilicity index (electron acceptor). This new reactivity index measures the stability of energy when it captures an extra electron charge $(\Delta N)$ from surrounding. Electrophilicity is a reactivity descriptor that accepts some natural Electrophilicity in relative scale. Recently, it's proven that this quantity can be used to assess the toxicity of various pollutants based on their reactivity and selected place [25] [26] [28] [29].

\section{Result and Discussion}

In this section, the relation between aromaticity and stability of various Oxidiasole's analogs in Figure 1 is investigated by different parameters including length of bonds, $G \Delta$, hardness, softness, as well as NICS and ASE 


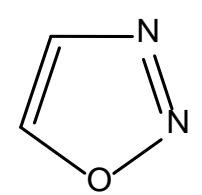

1,2,3-oxadiazole

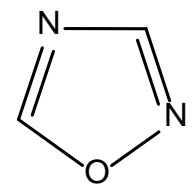

1,2,4-oxadiazole

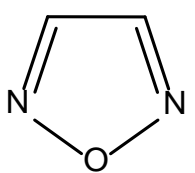

1,2,5-oxadiazole

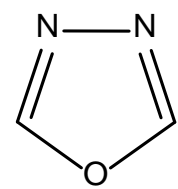

1,3,4-oxadiazole

Figure 1. Different Oxidiasole analogs.

computations. Furthermore, by comparing data and charts resulted from quantum mechanics computation it is tried to justify the stability of required molecules and their relation with aromaticity.

In analogs containing Oxygen atom i.e., oxadiasole components 1 to 4 , it is founded that the most stability is for component number 4, which has the smallest amount of free Gibs energy. Stability level of component number 1.

Component number 2 and component number 3 are 21.86, 8.64, and $40.61 \mathrm{kcal} / \mathrm{mol}$, respectively. According to the results, in analogs under investigation the stability level decreases as follows:

$4>2>1>3$

So that component number 4 is the most stable and component number 3 the least stable component (Table $1)$.

\subsection{Nucleus-Independent Chemical Shift (NICS)}

One of the factors which can affect the stability of a component is its aromaticity properties. In order to assess the aromatic property of these components, nucleus-independent chemical shift (NICS) method was used.

All computations are performed in GIAO-B3LYP/6-311+G** theoretical level.

The amounts calculated in NICS for each component can be negative or positive. Negative amounts state component's aromaticity, while positive amounts state anti-aromaticity of a component.

All components investigated in this study are aromatic because they all have negative NICS amounts.

For all components, NICS amounts in molecular center (NICS (0)) and in different distances on molecular surface had been calculated.

Results of NICS computations show the smallest amount for component number 4. According to these computations, the highest NICS amount belongs to component number 3 (Table 2).

\subsection{Aromatic Stability Energy (AES) [1]}

Aromatic stability energy is one of the methods used for studying aromatic properties of components. For this purpose, a series of isodesmic reactions are considered and aromatic stability energy (AES) amount is measured by Equation (5) [30]

$$
\mathrm{ASE}=G \sum \Delta \text { products }-\sum \Delta G \text { reactants }
$$

Results of this calculation are arranged in Table 3.

The more the amount of aromatic stability energy (ASE) is, the more stable is the component. Energic computations show that component number 4 is more stable, but ASE results cannot justify component number 4's stability. In Table 3, it can be observed that component number 4 is the most stable component with highest amount of hardness.

The more is the hardness of the molecule, the more stable it is. Considering the results in Table 4 the highest amount of hardness, 0.1327 , belongs to component number 4 . And the least hardness among the components belongs to component number 1 , with the amount of 0.1178 . The calculated results for molecule's hardness can justify component 4's stability compared to components 1,2 and 3.

As can be noticed in Table 4 the amounts of molecules' softness also decreased from components number 1 to 4 which can also confirm the stability of component 4 compared to other components.

\subsection{Length of Bond}

One of the most effective parameters that can justify stability is the length of bonds in a component. 


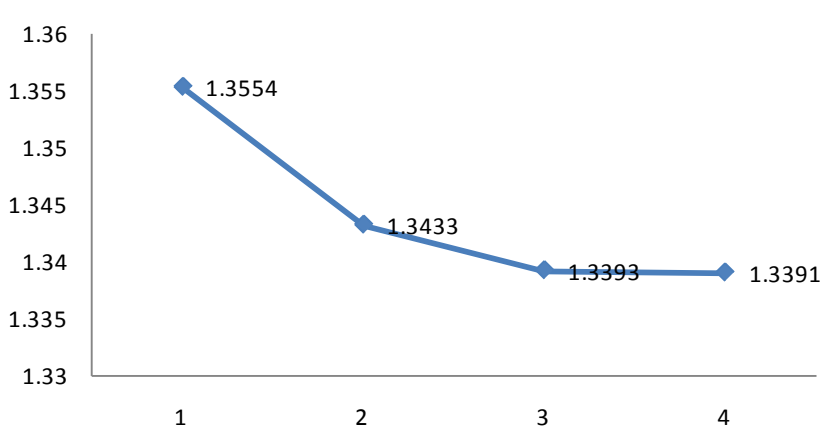

Chart 1. Measured average amounts forlength of bonds of components 1 to 4 from chem $3 d$.

Table 1. Calculated $\Delta G$ amounts for components 1 to 4, in kcal/mol on theoretical level GIAO-B3LYP/6-311+G**.

\begin{tabular}{ccccc} 
& $\mathbf{1 , 2 , 3 - o x a d i a z o l e}$ & $\mathbf{1 , 2 , 4 - 0 x a d i a z o l e}$ & $\mathbf{1 , 2 , 5}$-Oxadiazole & $\mathbf{1 , 3 , 4 - O x a d i a z o l e}$ \\
\hline$\Delta G$ & 21.86 & 8.64 & 40.61 & 0.00 \\
\hline
\end{tabular}

Table 2. Amounts results obtained in different distances for components 1 to 4 in GIAO-B3LYP/6-311+G** theoretical level.

\begin{tabular}{ccccc}
\hline NICS & $\mathbf{1 , 2 , 3 - o x a d i a z o l e}$ & $\mathbf{1 , 2 , 4 - 0 x a d i a z o l e}$ & $\mathbf{1 , 2 , 5 - O x a d i a z o l e ~}$ & $\mathbf{1 , 3 , 4 - O x a d i a z o l e ~}$ \\
\hline 0 & -13.69 & -11.85 & -13.82 & -11.10 \\
0.2 & -14.02 & -12.18 & -14.28 & -11.59 \\
0.4 & -14.59 & -12.74 & -15.12 & -12.42 \\
0.5 & -14.69 & -12.85 & -15.34 & -12.75 \\
0.6 & -14.58 & -12.77 & -15.31 & -12.68 \\
0.8 & -13.63 & -11.99 & -14.40 & -12.19 \\
\hline
\end{tabular}

Table 3. Calculated AES amounts for components 1 to 4, in $\mathrm{kcal} / \mathrm{mol}$ on theoretical level GIAO-B3LYP/6-311+G**.

\begin{tabular}{ccccc} 
& $\mathbf{1 , 2 , 3 - o x a d i a z o l e}$ & $\mathbf{1 , 2 , 4 - 0 x a d i a z o l e}$ & $\mathbf{1 , 2 , 5}$-Oxadiazole & $\mathbf{1 , 3 , 4 - O x a d i a z o l e}$ \\
\hline ASE & 38.20 & 9.54 & 6.05 & 9.06 \\
\hline
\end{tabular}

Table 4. Amounts of electronegativity $(X)$, hardness $(\eta)$, softness (S) calculated in electron volt (ev).

\begin{tabular}{ccccc}
\hline & $\mathbf{1 , 2 , 3 - 0 x a d i a z o l e}$ & $\mathbf{1 , 2 , 4 - 0 x a d i a z o l e}$ & $\mathbf{1 , 2 , 5 - O x a d i a z o l e ~}$ & $\mathbf{1 , 3 , 4 - O x a d i a z o l e ~}$ \\
\hline EHOMO & -0.300 & -0.311 & -0.313 & -0.305 \\
ELUMO & -0.064 & -0.060 & -0.058 & -0.039 \\
$\eta$ & 0.118 & 0.125 & 0.127 & 0.132 \\
$\mu$ & -0.182 & -0.185 & -0.186 & -0.172 \\
S & 8.482 & 7.947 & 7.854 & 7.531 \\
$\omega$ & 0.141 & 0.137 & 0.136 & 0.112 \\
\hline
\end{tabular}

In this study, the length of bonds' average parameter is measured and specified for each component and the results are demonstrated in Chart 1.

According to the results in this step component number 4 which is known as the most stable component has the least amount of length bonds, which is 1.3392 angstrom (Chart 1).

Therefore, the stability of component number 4 (Oxidiasole-1,3,4) can be justified based on the length of bonds. 


\section{Conclusion}

In components containing Oxygen, i.e. oxadiasoles 1 to 4, Component 4 is the most stable. This can be justified by the calculation of energy $(\Delta G)$, average of length of bonds, as well as hardness and softness; while NICS and ASE computations don't explain it.

\section{References}

[1] Di Mattia, M.A., Watts, N.R., Stahl, S.J., Grimes, J.M., Steven, A.C., Stuart, D.I. and Wingfield, P.T. (2013) Antigenic Switching of Hepatitis B Virus by Alternative Dimerization of the Capsid Protein. Structure, 21, 133-142. http://dx.doi.org/10.1016/j.str.2012.10.017

[2] Kovács, D., Wölfling, J., Szabó, N., Szécsi, M., Minorics, R., Zupkó, I. and Frank, É. (2015) Efficient Access to Novel Androsteno-17-(1',3',4')-Oxadiazoles and 17 $\beta$-(1',3',4')-Thiadiazoles via $N$-Substituted Hydrazone and $N, N^{\prime}$-Disubstituted Hydrazine Intermediates, and Their Pharmacological Evaluation in Vitro. European Journal of Medicinal Chemistry, 98, 13-29. http://dx.doi.org/10.1016/j.ejmech.2015.05.010

[3] Lin, K.-T., Lee, G.-H. and Lai, C.K. (2015) Mesogenic Heterocycles Formed by Bis-Pyrazoles and Bis-1,3,4-Oxadiazoles. Tetrahedron, 71, 4352-4361. http://dx.doi.org/10.1016/j.tet.2015.04.055

[4] Flipo, M., Desroses, M., Lecat-Guillet, N., Villemagne, B., Blondiaux, N., Leroux, F., Piveteau, C., Mathys, V., Flament, M.-P. and Siepmann, J. (2011) Ethionamide Boosters. 2. Combining Bioisosteric Replacement and StructureBased Drug Design to Solve Pharmacokinetic Issues in a Series of Potent 1,2,4-Oxadiazole EthR Inhibitors. Journal of Medicinal Chemistry, 55, 68-83. http://dx.doi.org/10.1021/jm200825u

[5] Omar, F., Mahfouz, N. and Rahman, M. (1996) Design, Synthesis and Antiinflammatory Activity of Some 1,3,4-Oxadiazole Derivatives. European Journal of Medicinal Chemistry, 31, 819-825. http://dx.doi.org/10.1016/0223-5234(96)83976-6

[6] Paraschivescu, C.C., Hădade, N.D., Coman, A.G., Gautier, A., Cisnetti, F. and Matache, M. (2015) Symmetrical and Non-Symmetrical 2,5-Diaryl-1,3,4-Oxadiazoles: Synthesis and Photophysical Properties. Tetrahedron Letters, 56, 39613964. http://dx.doi.org/10.1016/j.tetlet.2015.05.005

[7] Ghosh, P., Ternai, B. and Whitehouse, M. (1972) Potential Antileukemic and Immunosuppressive Drugs. 3. Effects of Homocyclic Ring Substitution on the in Vitro Drug Activity of 4-Nitrobenzo-2,1,3-Oxadiazoles (4-Nitrobenzofurazans) and Their N-Oxides (4-Nitrobenzofuroxans). Journal of Medicinal Chemistry, 15, 255-260. http://dx.doi.org/10.1021/jm00273a012

[8] Pace, A., Buscemi, S., Piccionello, A.P. and Pibiri, I. (2015) Advances in Heterocyclic Chemistry. Academic Press.

[9] Xiao, C. and Huang, Q. (2014) Inhibitory Effects of Two 1,3,4-Oxadiazoles on Larval Growth and $\alpha$-Amylase in the Midguts of Mythimna Separate Larvae. Journal of Asia-Pacific Entomology, 17, 251-256. http://dx.doi.org/10.1016/j.aspen.2013.11.009

[10] Baker, R. and Saunders, J. (1989) Article Annual Reports in Medicinal Chemistry. In: Richard, C.A., Ed., Annual Reports in Medicinal Chemistry, Academic Press, 31-40.

[11] Frei, R.W. and Lawrence, J.F. (1973) Fluorigenic Labelling in High-Speed Liquid Chromatography. Journal of Chromatography A, 83, 321-330. http://dx.doi.org/10.1016/S0021-9673(00)97048-1

[12] Yadagiri, B., Gurrala, S., Bantu, R., Nagarapu, L., Polepalli, S., Srujana, G. and Jain, N. (2015) Synthesis and Evaluation of Benzosuberone Embedded with 1,3,4-Oxadiazole, 1,3,4-Thiadiazole and 1,2,4-Triazole Moieties as New Potential Anti Proliferative Agents. Bioorganic \& Medicinal Chemistry Letters, 25, 2220-2224. http://dx.doi.org/10.1016/j.bmcl.2015.03.032

[13] Bajaj, S., Asati, V., Singh, J. and Roy, P.P. (2015) 1,3,4-Oxadiazoles: An Emerging Scaffold to Target Growth Factors, Enzymes and Kinases as Anticancer Agents. European Journal of Medicinal Chemistry, 97, 124-141. http://dx.doi.org/10.1016/j.ejmech.2015.04.051

[14] Zhang, W., He, W., Guo, X., Chen, Y., Wu, L. and Guo, D. (2015) Synthesis and Luminescence Properties of 1,3,4-Oxadiazole Acetamide Derivatives and Their Rare Earth Complexes. Journal of Alloys and Compounds, 620, 383-389. http://dx.doi.org/10.1016/j.jallcom.2014.09.153

[15] Bharty, M.K., Dani, R.K., Nath, P., Bharti, A., Singh, N.K., Prakash, O., Singh, R.K. and Butcher, R.J. (2015) Polyhedron, 98, 84-95.

[16] Bokor, É., Fekete, A., Varga, G., Szőcs, B., Czifrák, K., Komáromi, I. and Somsák, L. (2013) C-( $\beta$-d-Glucopyranosyl) formamidrazones, Formic Acid Hydrazides and Their Transformations into 3-( $\beta$-d-Glucopyranosyl)-5-Substituted1,2,4-triazoles: A Synthetic and Computational Study. Tetrahedron, 69, 10391-10404. http://dx.doi.org/10.1016/j.tet.2013.09.099

[17] Chahkandi, B., Tayyari, S.F., Bakhshaei, M. and Chahkandi, M. (2013) Investigation of Simple and Water Assisted 
Tautomerism in a Derivative of 1,3,4-Oxadiazole: A DFT Study. Journal of Molecular Graphics and Modelling, 44, 120-128. http://dx.doi.org/10.1016/j.jmgm.2013.04.002

[18] Srinivas, K., Sivakumar, G., Ramesh Kumar, C., Ananth Reddy, M., Bhanuprakash, K., Rao, V.J., Chen, C.-W., Hsu, Y.-C. and Lin, J.T. (2011) Novel 1,3,4-Oxadiazole Derivatives as Efficient Sensitizers for Dye-Sensitized Solar Cells: A Combined Experimental and Computational Study. Synthetic Metals, 161, 1671-1681. http://dx.doi.org/10.1016/j.synthmet.2011.06.001

[19] Wang, G.-X., Shi, C.-H., Gong, X.-D., Zhu, W.-H. and Xiao, H.-M. (2009) Packing Structures and Periodic Band Calculations on DPO (2,5-Dipicryl-1,3,4-oxadiazole). Journal of Hazardous Materials, 169, 813-818. http://dx.doi.org/10.1016/j.jhazmat.2009.04.024

[20] El-Azhary, A.A. (1996) Vibrational Analysis of the Spectra of 1,3,4-Oxadiazole, 1,3,4-Thiadiazole, 1,2,5-Oxadiazole and 1,2,5-Thiadiazole: Comparison between DFT, MP2 and HF Force Fields. Spectrochimica Acta Part A: Molecular and Biomolecular Spectroscopy, 52, 33-44. http://dx.doi.org/10.1016/0584-8539(95)01535-3

[21] Palmer, M.H. (2009) The Electronic States of 1,2,5-Oxadiazole Studied by VUV Absorption Spectroscopy and CI, CCSD(T) and DFT Methods. Chemical Physics, 360, 150-161. http://dx.doi.org/10.1016/j.chemphys.2009.04.021

[22] Parr, R.G. and Yang, W. (1995) Density-Functional Theory of the Electronic Structure of Molecules. Annual Review of Physical Chemistry, 46, 701-728. http://dx.doi.org/10.1146/annurev.pc.46.100195.003413

[23] Garza, J. and Robles, J. (1993) Density-Functional-Theory Softness Kernel. Physical Review A, 47, 2680-2685. http://dx.doi.org/10.1103/PhysRevA.47.2680

[24] Lozovoi, A., Alavi, A., Kohanoff, J. and Lynden-Bell, R. (2001) Ab initio Simulation of Charged Slabs at Constant Chemical Potential. The Journal of Chemical Physics, 115, 1661-1669. http://dx.doi.org/10.1063/1.1379327

[25] Lu, H. and He, D. (2014) Novel 2-(Naphthalen-1-yl)-5-stilbene-1,3,4-oxadiazole Molecules: Synthesis, Optical Properties and DFT Calculation. Journal of Molecular Structure, 1060, 88-93. http://dx.doi.org/10.1016/j.molstruc.2013.12.022

[26] Sun, F. and Jin, R. (2013) dft and td-dft Study on the Optical and Electronic Properties of Derivatives of 1,4-bis(2substituted-1,3,4-oxadiazole)benzene. Arabian Journal of Chemistry.

[27] Chattaraj, P.K., Gutierrez-Oliva, S., Jaque, P. and Toro-Labbe, A. (2003) Towards Understanding the Molecular Internal Rotations and Vibrations and Chemical Reactions through the Profiles of Reactivity and Selectivity Indices: An $A b$ initio SCF and DFT Study. Molecular Physics, 101, 2841-2853. http://dx.doi.org/10.1080/0026897032000112900

[28] Al-Omary, F.A.M., Karakaya, M., Sert, Y., Haress, N.G., El-Emam, A.A. and Çırak, Ç. (2014) Structural and Spectroscopic Analysis of 3-[(4-Phenylpiperazin-1-yl)methyl]-5-(thiophen-2-yl)-2,3-dihydro-1,3,4-oxadiazole-2-thione with Experimental (FT-IR, Laser-Raman) Techniques and Ab initio Calculations. Journal of Molecular Structure, 1076, 664-672. http://dx.doi.org/10.1016/j.molstruc.2014.08.035

[29] Hegelund, F., Larsen, R.W., Aitken, R.A., Aitken, K.M. and Palmer, M.H. (2007) High-Resolution Infrared and Theoretical Study of Four Fundamental Bands of Gaseous 1,3,4-Oxadiazole between 800 and $1600 \mathrm{~cm}^{-1}$. Journal of Molecular Spectroscopy, 246, 198-212. http://dx.doi.org/10.1016/j.jms.2007.09.011

[30] De Proft, F. and Geerlings, P. (2001) Conceptual and Computational DFT in the Study of Aromaticity. Chemical Reviews, 101, 1451-1464. http://dx.doi.org/10.1021/cr9903205 